\title{
Users' Application Persistence Analysis of Short Video based on Technology Acceptance Model
}

\author{
Jia Ke ${ }^{1}$, Weiji Wang ${ }^{1}$, Xiao-Jun Chen ${ }^{2+}$, Yaxin Ren ${ }^{1}$ and Jian-Ping Gou ${ }^{3}$ \\ ${ }^{1}$ School of management Jiangsu University, Zhenjiang, China \\ ${ }^{2}$ Affiliated Hospital of Jiangsu University, China \\ ${ }^{3}$ School of computer science of Jiangsu University, China
}

\begin{abstract}
With the development of network technology and the wide use of mobile terminals, short video has become the main carrier of people's understanding of the world, for information analysis and social interaction. It is one of the main ways for short video application platform to improve users' experience, enhance users' continuous use intention, and improve design functions. This paper constructs a technology acceptance model based on Perceived availability, Perceived ease of use, Users' satisfaction perception behavior, Value perception, Willingness to use, these five dimensions. The results show that Perceived availability, Perceived ease of use, Users' satisfaction perception behavior have a direct positive impact on users' satisfaction and willingness to use, which provides a good theoretical basis and practical guidance for short video applications to effectively improve users' stickiness.
\end{abstract}

Keywords: Technology Acceptance model, short video application, users' stickiness

\section{Background}

With the rapid development of mobile Internet and big data technology, all kinds of short video application are characterized by short, flat and fast, providing people for a new information dissemination and sharing platform. Since 2016, various short video applications emerged rapidly in China, such as Tiktok, Kwai video, Watermelon video and so on. In 2020, WeChat also launched a video sharing function. Playing short video with a length of 15-20 seconds has a profound and diversified impact on people's information access, information interaction channels, daily living habits and consumption patterns. And short video has a tendency to play for one minute or even longer, which means that the amount of information it brings to people will be doubled or even more. The development of science and technology promotes social progress, and people interact with each other through network sharing to meet social needs.

The mount of active Tiktok video users are 6,133,390,000, and the mount of active users of Kwai video, is 4,667,820,000 [1]. In Tiktok, '2018 research report' shows that over 1340 media accounts were registered on the 2018, and more than 150 thousand short videos were distributed, which was released by the Press Association of China, published in the first year of the media: The total number of broadcast media was over 77 billion 560 million, So 2018 was called the first year of the 'Tiktok' trembling eruption [2].

The short video coverage of college students is almost the same as that of the whole people. They have specific needs for short video application. Information sharing, personal value embodiment and social interaction demand drive them to obtain these specific needs through short video application. Short video application also provides users with a variety of functional options, including video effects, video props, album production, and various types of background music selection, music editing and other video production templates and so on. While expressing themselves through short video application, college students will also hope to get more attention, praise and comments on the platform, so as to realize the needs of social interaction and communication sharing, and realize the smooth exchange of information with the external environment [3]. According to the 45th statistical report on the development of Internet in China [4], as of March 2020, the number of Internet users in China is 904 million, of which students account for 26.9\%,

\footnotetext{
+ Corresponding author. Tel.: + (86)13912806378;

E-mail address: cxj@ujs.edu.cn.
} 
and the number of short video users has reached 773 million, an increase of 125 million over the end of 2018, accounting for $85.6 \%$ of the total Internet users. According to 'White paper on short video content marketing trends in 2020', the number of active users in January 2020 has reached 400 million, of which 18-24 years old users are most active Tiktok [5].

Therefore, many short video application platforms, how to retain users in such a large group, design the function of attracting users, enhance the users' experience and their willingness to use, and also keep them continuously for a long time. This paper mainly studies the users' experience of college students, who use the short-term frequency platform, aiming to analyse the users' needs and improve the users' stickiness for making decision and advice.

\section{Technology Acceptance Model}

Davis proposed the Technology Acceptance Model (TAM) in 1989. The TAM explains the acceptance behavior by the user's perception of technology, which is used to explain the acceptance behavior of users' information system. The performance usefulness and the perceived ease of use are two most important predictive variables in the model, influenced by a series of external variables. Perceived usefulness refers to the degree of improving the efficiency and performance after using the system, and perceived usability refers to the difficulty of using the system. When users' perceive that the information system is simple and convenient, and can also improve the efficiency of the work, the user will continue to use the system. Nowadays, the theory of technology acceptance model is widely used in the research of users' behavior in different fields such as database, e-commerce, digital library and mobile application.

Continuous using intention refers to the degree of users' willingness to use a product continuously. The usage and satisfaction theory, planning theory, rational behavior theory, expectation confirmation model and technology acceptance model are used to study the common theoretical basis of users' continuous intention [6-10]. Taking college students as the research object, this paper analyzes the relevant impact on users' satisfaction and continuous using intention from the aspects of short video application interface design, functional experience, college students' social needs, value perception, etc [11], constructs a model of college students' short video app behavior intention by technology acceptance model, as shown in Figure 1.

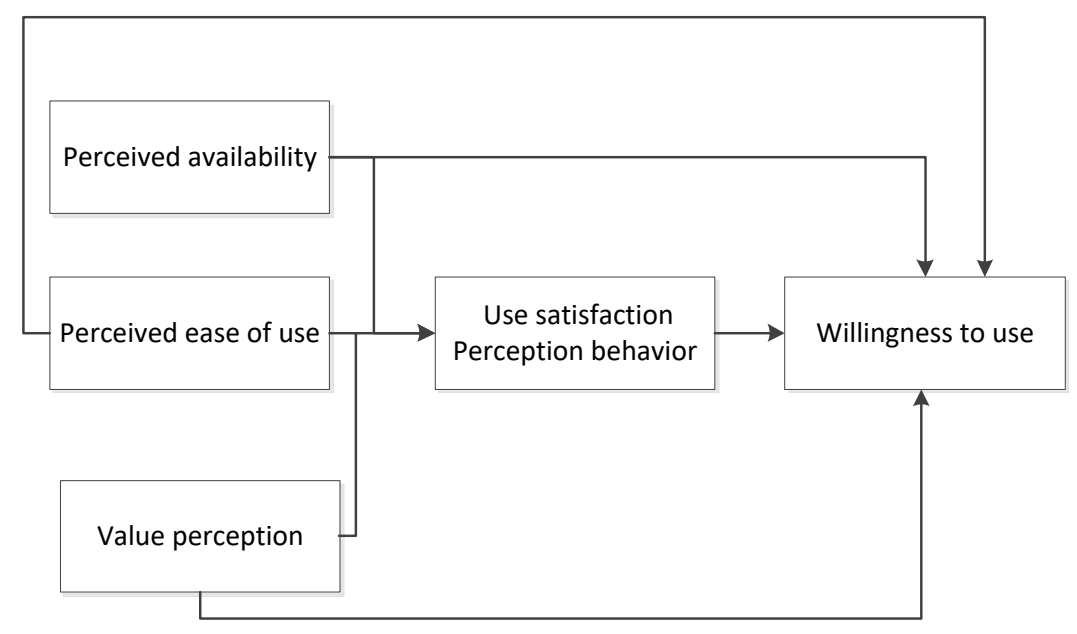

Fig. 1: Technical Acceptance Module

\section{Model Construction and Research Hypothesis}

\subsection{Perceived Availability}

In the technology acceptance model constructed in this paper, perceived usefulness, equals to perceived availability (PA), means that when the short video app meets the users' needs and social needs, the users' perceives that the platform function is useful and the users' satisfaction will be improved. In this study, perceived availability includes: automatic push function, custom like function, friend related push function, friend visible function, view visible function and advertisement push function. According to TAM model, users are willing to use an information technology because of its use value and perceived usefulness. 
Therefore, the research hypothesis is put forward: there is a positive correlation between perceived availability and users' satisfaction perception behavior (H1); there is a positive correlation between perceived availability and willingness to use (H2).

\subsection{Perceived Fase of Use}

Perceived ease of use (PE) is used to describe the time users feel they need to pay, or the cost of effort. In this study, it refers to the degree of difficulty perceived by users when using short video app, such as software interface design, functions, viewing visual experience, etc. Users can perceive the usefulness while they perceive the ease of use, which also improves the users' satisfaction. Furthermore, users are more willing to continue to use the short video app, produce and upload videos.

Therefore, the research hypothesis is put forward: there is a positive correlation between perceived ease of use and users' satisfaction perception behavior (H3); there is a positive correlation between perceived ease of use and willingness to use $(\mathrm{H} 4)$.

\subsection{Value Perception}

Value perception (VP) refers to the use of certain functions to help users get the value of their own experience. For example, you can get a certain amount of reading and likes for your own videos, pay for live broadcast, and attract traffic. There is also the function of providing paid promotion and improving traffic. After obtaining these functions, users can improve the flow reading of their works. Thus, further activities can be carried out, such as live broadcasting with goods, promoting works, and improving users' satisfaction, which will be used continuously.

Therefore, the research hypothesis is put forward: There is a positive correlation between value perception and users' satisfaction perception behavior (H5); there is a positive correlation between value perception and willingness to use (H6).

\subsection{Users Perception Behavior Satisfaction}

Users' Perception behavior satisfaction (US) is used to measure the actions that they can obtain in the actual using process, including making video, uploading video, making special effects, movie set function, music editing, live broadcast function, live broadcast PK function, etc. In the process of using the functions the users' experience can directly perceive the behavior satisfaction.

Therefore, the research hypothesis is put forward: there is a positive correlation between users' Perception behavior satisfaction and willingness to use (H7).

\subsection{Willingness to Use}

Willingness to use (VTU) is used to describe users' willingness to use software, including willingness to share life, social communication, comment and like function. Using short video software for self-display and social sharing; get happiness after use, willing to continue to use. The potential variables of perceived availability, perceived ease of use, users' satisfaction perception behaviour, value perception have a significant impact on intention to use.

\section{Research Design and Data Analysis}

The empirical research is completed by designing, distributing, collecting and analyzing questionnaires. The questionnaire is designed in the form of Likert five point scales. The level 1-5 indicates the user's satisfaction with the short video application, which is very like, relatively like, indifferent, not very acceptable and intolerable. The questionnaire used five dimensional variables, they are: Perceived ease of use (PE), Perceived availability (PA), Value perception (VP), Users' satisfaction perception behavior (US), Willingness to use (VTU), a total of 24 questions. In this study, questionnaires were sent out to college students. 169 valid questionnaires were collected on the website of questionnaire star. In the questionnaire, $49.1 \%$ of boys and $50.9 \%$ of girls participated. This group is one of the main users, and representative. In their spare time of study, such as lunch break, before going to bed and eating, they will watch videos, and in the spare time and rest day, they will edit and make short videos. It is the main crowds who will choose to click, watch, forward and participate in the production and usage. 


\subsection{Reliability Analysis}

In this paper, SPSS was used to test the reliability and validity. Reliability is used to measure whether the data scale is consistent or whether the data is stable. As shown in Table 1, the Cronbach's alpha coefficient of each dimension is calculated, and the values are between 0.781 and 0.899 , all greater than 0.7. The total Cronbach's alpha coefficient of the questionnaire is 0.945 , which is in the ideal range. Internal consistency reliability: composite reliability (CR) should be higher than 0.7 . The $\mathrm{CR}$ values of five factors ranged from 0.7717 to 0.9032 , all higher than 0.7 . It shows that the questionnaire has good internal consistency and high data reliability.

\subsection{Validity Analysis}

Validity analysis is generally used to measure the deviation between the measured data and the true value of the questionnaire. As shown in Table 2, for each item of potential variable, the factor load coefficient is greater than 0.7 , which is in the ideal range. Convergent validity: the average variance extracted (AVE) should be higher than 0.5. The AVE values of five potential variables in this study are between 0.5209 and 0.673 . Discriminant validity: the AVE square of each potential factor should be higher than the highest correlation between the factor and any other factors. As shown in Table 3, the discriminant validity of the five factors met this condition. To sum up, the research model has good reliability and validity. The factors have good discriminant validity. Data analysis shows that there are differences among the potential variables, which indicates that good differences between the options of the questionnaire design.

Table 1: List of items in each dimension, Cronbach's alpha, combination reliability and average value of the model

\begin{tabular}{|c|c|c|c|c|}
\hline Latent variable & Number of items & Cronbach' s Alpha & CR & AVE \\
\hline PE & 4 & 0.897 & 0.892 & 0.673 \\
\hline PA & 6 & 0.839 & 0.841 & 0.5209 \\
\hline VP & 4 & 0.781 & 0.7717 & 0.5615 \\
\hline US & 7 & 0.899 & 0.9032 & 0.5758 \\
\hline VTU & 3 & 0.842 & 0.8448 & 0.645 \\
\hline
\end{tabular}

Table 2: Standardized factor load of potential variable test items

\begin{tabular}{|c|c|c|c|c|c|}
\hline $\begin{array}{c}\text { Latent } \\
\text { variable }\end{array}$ & $\begin{array}{l}\text { Measurement } \\
\text { questions }\end{array}$ & $\begin{array}{l}\text { Standardized } \\
\text { factor load }\end{array}$ & $\begin{array}{c}\text { Latent } \\
\text { variable }\end{array}$ & $\begin{array}{l}\text { Measurement } \\
\text { questions }\end{array}$ & $\begin{array}{l}\text { Standardized } \\
\text { factor load }\end{array}$ \\
\hline \multirow{4}{*}{ PE } & PE1 & 0.808 & \multirow{7}{*}{ US } & US1 & 0.773 \\
\hline & PE2 & 0.877 & & US2 & 0.746 \\
\hline & PE3 & 0.811 & & US3 & 0.835 \\
\hline & PE4 & 0.783 & & US4 & 0.854 \\
\hline \multirow{6}{*}{$\mathrm{PA}$} & PA1 & 0.583 & & US5 & 0.85 \\
\hline & PA2 & 0.602 & & US6 & 0.614 \\
\hline & PA3 & 0.735 & & US7 & 0.592 \\
\hline & PA4 & 0.746 & \multirow{3}{*}{ VTU } & VTU1 & 0.824 \\
\hline & PA5 & 0.724 & & VTU2 & 0.818 \\
\hline & PA6 & 0.698 & & VTU3 & 0.766 \\
\hline \multirow{2}{*}{ VP } & VP1 & 0.754 & \multirow{2}{*}{ VP } & VP3 & 0.680 \\
\hline & VP2 & 0.754 & & VP4 & 0.581 \\
\hline
\end{tabular}

Table 3: Discriminant validity

\begin{tabular}{|c|c|c|c|c|c|}
\hline & PE & PA & VP & US & VTU \\
\hline PE & 0.673 & & & & \\
\hline PA & 0.299 & 0.5209 & & & \\
\hline VP & 0.292 & 0.423 & 0.5615 & & \\
\hline US & 0.374 & 0.381 & 0.332 & 0.5758 & \\
\hline VTU & 0.269 & 0.381 & 0.349 & 0.381 & 0.645 \\
\hline Square root of AVE & 0.820 & 0.722 & 0.749 & 0.759 & 0.803 \\
\hline
\end{tabular}




\subsection{Structural Model Analysis Results}

In this paper, Amos 23 is used to analyze the theoretical hypothesis, and the maximum likelihood method is used to estimate the parameters, fit and test the hypothesis of the structural equation model. The fitting value after model modification is shown in Table 4. The overall fit is good and meets the parameter standard. As shown in Table 5, the results of structural equation model show that all path coefficients are significant. It shows that software usability, ease of use and value perception is positively correlated with users' satisfaction and willingness to use. The users' satisfaction is also positively related to the willingness to use.

Table 4: Overall fitting coefficient table

\begin{tabular}{|l|c|c|c|c|c|c|}
\hline Fitting index & $\chi 2 / \mathrm{df}$ & RMSEA & GFI & AGFI & CFI & IFI \\
\hline Ideal value & $<2.00$ & $<0.08$ & $>0.90$ & $>0.90$ & $>0.90$ & $>0.90$ \\
\hline Acceptable value & $<3.00$ & $<0.10$ & $>0.70$ & $>0.70$ & $>0.80$ & $>0.80$ \\
\hline The value of this study & 2.637 & 0.099 & 0.802 & 0.81 & 0.840 & 0.843 \\
\hline
\end{tabular}

Table 5: Validation results of structural equation hypothesis

\begin{tabular}{|c|c|c|c|c|c|c|}
\hline Hypothesis & Relationship & Estimate & SE & CR & P Significance & Result \\
\hline H1 & US <- PA & 0.381 & 0.07 & 5.418 & $* * *$ & $\begin{array}{c}\text { establis } \\
\text { hed }\end{array}$ \\
\hline H2 & VTU <- PA & 0.349 & 0.065 & 5.334 & $* * *$ & established \\
\hline H3 & US <- PE & 0.374 & 0.06 & 6.187 & $* * *$ & established \\
\hline H4 & VTU <- PE & 0.381 & 0.06 & 6.352 & $* * *$ & established \\
\hline H5 & US <- VP & 0.332 & 0.064 & 5.185 & $* * *$ & established \\
\hline H6 & VTU <- VP & 0.381 & 0.07 & 5.427 & $* * *$ & established \\
\hline H7 & VTU <- US & 0.269 & 0.053 & 5.106 & $* * *$ & established \\
\hline
\end{tabular}

\section{Discussion}

As a phenomenal form of communication in today's mobile Internet era, short video has had a profound and diversified impact on information access, information interaction channels, daily living habits and consumption patterns. This paper analyzes the process of using short video app from college students, by the technology acceptance model. From the results of data analysis, it can be found that from the perspective of users, the usability functions provided by the application, such as automatic push, personalized customization and other functions, have a positive impact on users' satisfaction and willingness to use, In the structural equation, the path coefficients were $0.381(\mathrm{P}<0.001)$ and $0.349(\mathrm{P}<0.001)$. At the same time, the ease of use of APP function design interface and function module layout are also important factors that positively affect users' satisfaction and willingness to use. The path coefficients are $0.332(\mathrm{P}<0.001)$ and 0.381 ( $\mathrm{P}<0.001$ ), respectively. In addition, users can experience the embodiment of their own value from the view function of their works being praised and read, so as to improve their satisfaction.

From the perspective of short video app designers, we can improve the usability and ease of use of the software itself, such as in-depth study of personalized customization function, analysis of users' historical data, establishment of users' interesting model, more accurately push interested videos to users, improve users' satisfaction, and extend users' willingness to use the app. In the function layout setting, the design is more friendly, simple and easy to operate, the function module layout reasonable interface, improve the users' experience. Add functions that can enhance the user's value perception, such as increasing the interaction in the live link, and the like, comment and evaluation functions in the PK link. So as to enhance the user's willingness to use, so that users can continue to use the product, improve the user's stickiness to the product.

\section{Acknowledgements}

This research is supported by the Opening Project of Shanghai Key Laboratory of Integrated Administration Technologies for Information Security, Subject number: AGK2020002. National Natural Science Foundation of China: 61976107. 


\section{References}

[1] Feigua data. Short video ecological service platform[OL]. https:// ks2.Feigua.cn/.

[2] A summary of Tiktok short video audience research[J]. Today's Massmedia.2021,2: 26-29.

[3] Wang kefu. Tiktok based on $5 \mathrm{~W}$ mode analysis of the characteristics of government account transmission -- take "couch cloth" as an example [J]. New media research. 2018, 4(19), 23-25.

[4] http://www.cac.gov.cn/2020-04/27/c_1589535470378587.htm

[5] https://www.caasdata.com/.

[6] Xu shun,Tian xiaoxiang, Research on Influencing Factors of users' willingness to use online learning platform based on TAM[J]. China's education informatization. 2020(8):78-85.

[7] Ye H,Li R,Geng M.Research on the factors of affecting the Mobile Learning[J]. Third International Sympo-sium on Knowledge Acquisition and Modeling.IEEE,2010:313-316.

[8] Hao S,Dennen V P,Mei L.Influential factors formobile learning acceptance among Chinese users[J].Educa-tional Technology Research \& Development.2017, 65 (1):101-123.

[9] Ayman Almukhlifi, Hepu Deng, and Booi Kam, E-Government adoption in Saudi Arabia: The moderation influence of transparency[J]. Journal of Advances in Information Technology. 2019, 10(1):1-8.

[10] Hiroki Yoshida, Seiji Tani, Jitsuko Masui, etc. A comparative study on Japanese and Korean students' perceived usefulness of online cooperative leaning[J]. Journal of Advances in Information Technology. 2015, 6(3):161-166. Doi:10.12720/jait.6.3.161-166.

[11] Fu ying, Hou xinjie. Research on factors influencing user willingness to use tiktok short video[C]. Proc. of 2020Remix Education Conference,2020,8. 